\title{
Endoscopic Retrieval of Flanged Ventricular Catheters
}

\author{
M. Ege Babadagli, Dwaine Cooke, Simon A. Walling, P. Daniel McNeely
}

\begin{abstract}
Flanged ventricular catheters are now used infrequently. Many patients with longstanding hydrocephalus still harbor these catheters, either as their current ventricular catheter, or as a retained catheter from a prior implant. The removal of flanged ventricular catheters is sometimes necessary, and may be challenging due to intraventricular adhesions. We describe the use of an endoscopic technique for the successful retrieval of flanged ventricular catheters in two patients. The technique described in this report may be helpful for patients that have flanged ventricular catheters that must be removed.
\end{abstract}

RÉSUMÉ: Extraire des cathéters ventriculaires à brides par voie endoscopique. Les cathéters ventriculaires à brides sont désormais rarement utilisés. De nombreux patients atteints, de longue date, d'hydrocéphalie continuent encore aujourd'hui à être munis de ces cathéters. À noter qu'il s'agit parfois de cathéters ayant été maintenus en place à la suite d'une pose antérieure. L'extraction de ces cathéters devient parfois nécessaire et peut s'avérer difficile en raison d'adhésions intraventriculaires. Nous voulons décrire ici l'utilisation d'une technique endoscopique ayant permis, dans le cas de deux patients, d'extraire avec succès leurs cathéters. En somme, il se pourrait que la technique décrite dans ce compte-rendu soit bénéfique.

Keywords: Hydrocephalus, Cerebrospinal Fluid Shunts, Neuroendoscopy

doi:10.1017/cjn.2018.336

Can J Neurol Sci. 2018; 45: 692-695

Flanged ventricular catheters were introduced in an effort to reduce shunt failure, ${ }^{1}$ and were used commonly during the 1970 s to treat adult and pediatric hydrocephalus patients. The flanges of these catheters were intended to fold back over the catheter holes and shield them from obstruction by brain parenchyma during insertion of the catheter. Following placement within the ventricles, the flanges were designed to spring open and protect the catheter holes from occlusion by choroid plexus. ${ }^{2}$ Flanged catheters have not definitively reduced shunt obstruction rates. Rather, flanged shunt catheters proved problematic when a shunt revision was required, due to the adhesions that form around the flanges, leading to an increased risk of choroid plexus avulsion when removed. ${ }^{3}$ By the mid-1980s, the use of flanged catheters was being discouraged. ${ }^{4}$ Flanged catheters are now used infrequently, but were being sold in Canada as recently as 2018 (personal communication with Medtronic sales and marketing representatives).

Many patients with longstanding hydrocephalus still harbor these flanged catheters, either as their current ventricular catheter, or as a retained catheter from a prior implant. The removal of retained flanged ventricular catheters is sometimes necessary, and may be challenging due to adhesions that anchor the flanged portion of the catheter. We report an endoscopic retrieval technique for the safe removal of retained flanged ventricular catheters.

The first patient has cerebral palsy, autism, and congenital hydrocephalus treated with a ventriculoperitoneal (VP) shunt in infancy. At 15 years of age, he presented with increasing lethargy and decreased oral intake. On imaging, a fracture in the proximal portion of his VP shunt was identified, along with increased ventricle dimensions when compared with a prior baseline scan.
The shunt system, which consisted of a flanged ventricular catheter, a burr hole valve, and peritoneal catheter, was revised. At surgery, the ventricular catheter had retracted from the cortical surface and was left in situ. A completely new VP shunt system was placed. After a period of 39 days, the patient returned with fever, an elevated white blood cell count of $15.6 \times 10^{9} / \mathrm{L}$ (reference range $4.0-11.0 \times 10^{9} / \mathrm{L}$ ), and an elevated C-reactive protein of $166.6 \mathrm{mg} / \mathrm{L}$ (reference range $0-5 \mathrm{mg} / \mathrm{L}$ ). The shunt was tapped and unidentified gram-positive cocci in pairs were seen. CSF culture ultimately grew coagulase-negative staphylococcus. The shunt was externalized and the patient was treated with intravenous antibiotics. After a period of 15 days later, following confirmation of negative CSF cultures, the patient returned to the operating room. In an effort to reduce the risk of re-infection, it was decided to remove all existing shunt components including the retained flanged ventricular catheter that was disconnected and retracted from the cortical surface (Figures 1A-1D). The flanged catheter was removed endoscopically.

The endoscopic procedure involved navigated (Medtronic StealthStation, Louisville, Colorado, USA) cannulation of the right lateral ventricle with an 18 -French peel-away introducer, via

From the Faculty of Medicine, Dalhousie University, Halifax, Canada (MEB); Division of Neurosurgery, Kingston Public Hospital, Kingston, Jamaica (DC); Division of Neurosurgery (Department of Surgery), IWK Health Centre, Dalhousie University, Halifax, Canada (SAW, PDM).

Received May 7, 2018. Final Revisions Submitted August 8, 2018. Date of AcCeptance August 11, 2018.

Correspondence to: P. Daniel McNeely, Division of Neurosurgery, IWK Health Centre, 5850 University Avenue, P.O. Box 9700, Nova Scotia, Canada B3K 6R8.

Email: dmcneely@dal.ca 

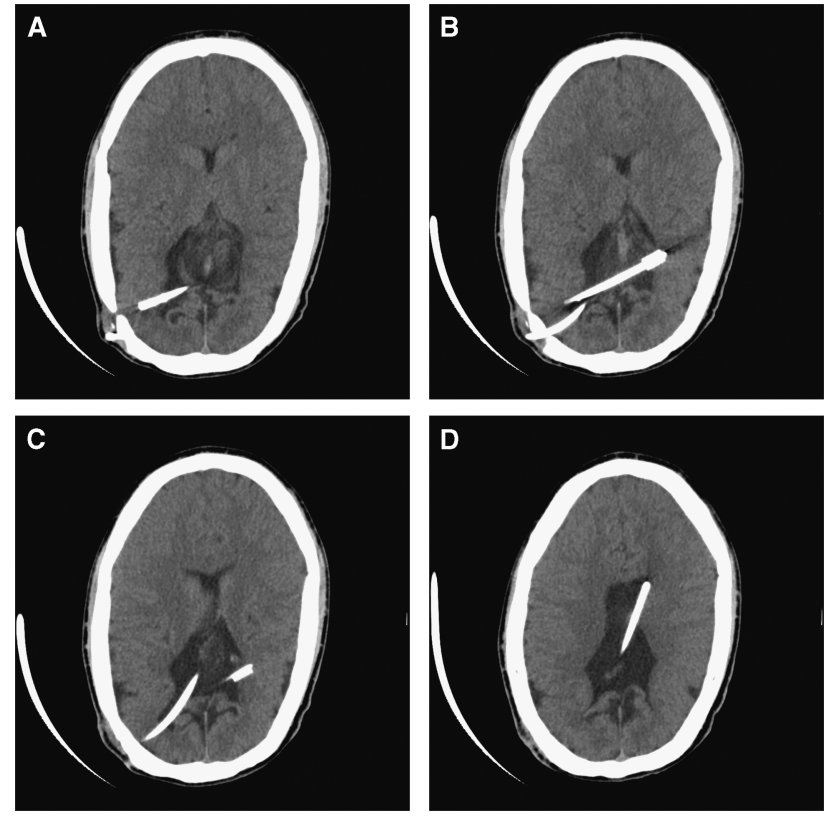

Figure 1: Patient 1. (A-D) Axial CT scan images of the brain demonstrating a retained finned ventricular catheter (Integra LifeSciences Corporation) that has retracted from the cortical surface.
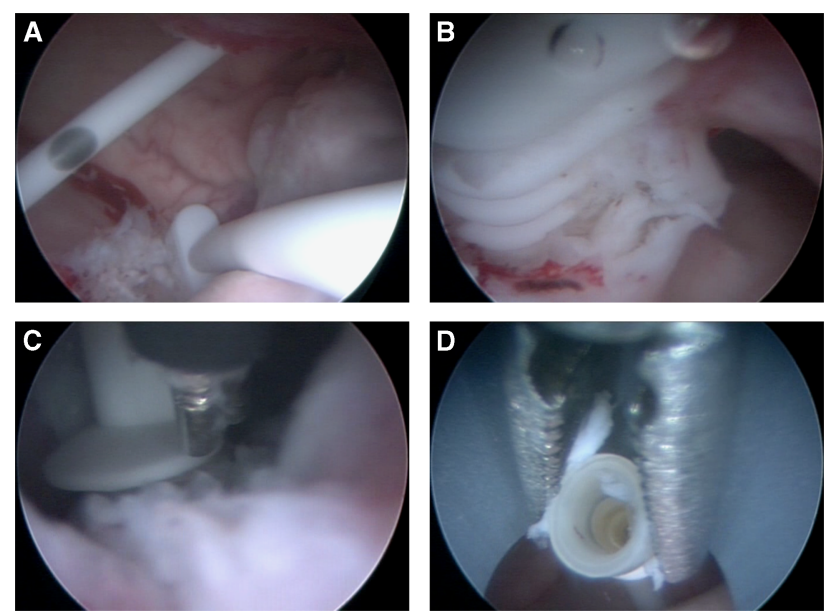

Figure 2: The sequential steps taken to mobilize and remove the adherent flanged ventricular catheter in Patient 1 . (A) and (B) The flanged catheter is seen, and is adherent to the choroid plexus. (C) An endoscopic bipolar electrocoagulator is used to release adhesions that are anchoring the catheter in place. (D) The flanged ventricular catheter is retrieved by grasping its distal (open) end with forceps and removed via the endoscopic port.

a right posterior parietal burr hole, and introduction of a MINOP Aesculap $30^{\circ}$ angled scope. The flanged tip of the catheter was immediately visualized in the left lateral ventricle through a defect in the septum pellucidum. The flanges were adherent to the ependymal surface of the ventricle and to the choroid plexus (Figures 2A and 2B). The flanges were successfully dissected free of their adhesions to these structures through the use of an endoscopic bipolar (Figure 2C), and the flanged tip of the catheter was further mobilized via endoscopic scissors and blunt-tipped endoscopic forceps. The retrieval and removal of the flanged
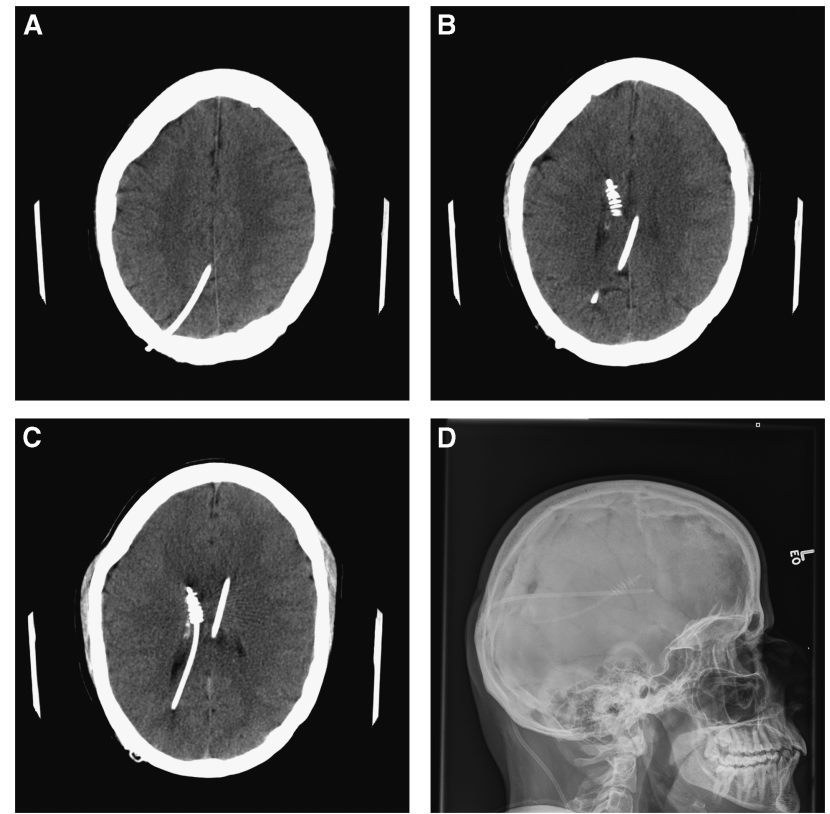

Figure 3: Patient 2. (A-C) Axial CT scan images of the brain with the retained Portnoy flanged ventricular catheter (Integra Lifesciences Corporation), retracted at its distal end from the cortical surface. (D) A scout X-ray image that demonstrates both the patient's current standard ventricular catheter as well as the flanged catheter.

ventricular catheter was successfully achieved via the 18-French peel-away sheath, by applying traction to the catheter's open distal end (Figure 2D). A completely new VP shunt system was subsequently placed under the same anesthetic. There were no peri-operative complications, and the patient has not had any further shunt operations in over 7 years of follow-up.

The second patient is a 41-year-old who has spina bifida, with multiple prior shunt revisions. He presented with a 3 -week history of fever, chills, abdominal discomfort, and a foreign body sensation in his rectum. On examination, the distal portion of the shunt system was found to be protruding through the patient's anus. The shunt was externalized and general surgery was performed via laparotomy. A perforation was found at the distal sigmoid/proximal rectum and the fistula was repaired. The patient was treated with intravenous antibiotics. The CSF infection (Enterococcus faecalis and Escherichia coli) persisted on serial CSF samples 16 days later. Imaging revealed a flanged ventricular catheter with retraction of the distal end away from the cortical surface (Figures 3A-3D). This was a retained catheter that was no longer being used but remained within the patient's right lateral ventricle. Endoscopic removal of the flanged ventricular catheter was performed, followed by placement of a new external ventricular drain.

The endoscopic procedure involved navigated (Medtronic StealthStation) cannulation of the right lateral ventricle with an 18-French peel-away introducer, via a right frontal burr hole, and introduction of a MINOP Aesculap $30^{\circ}$ angled scope. The flanged catheter was seen and was adherent to the ependymal lining of the ventricle as well as the choroid plexus (Figure 4A). An endoscopic bipolar cautery was used to release the adherent bands and choroid plexus attachments that were anchoring the catheter in place (Figure 4B). The use of scissors and blunt-tipped 

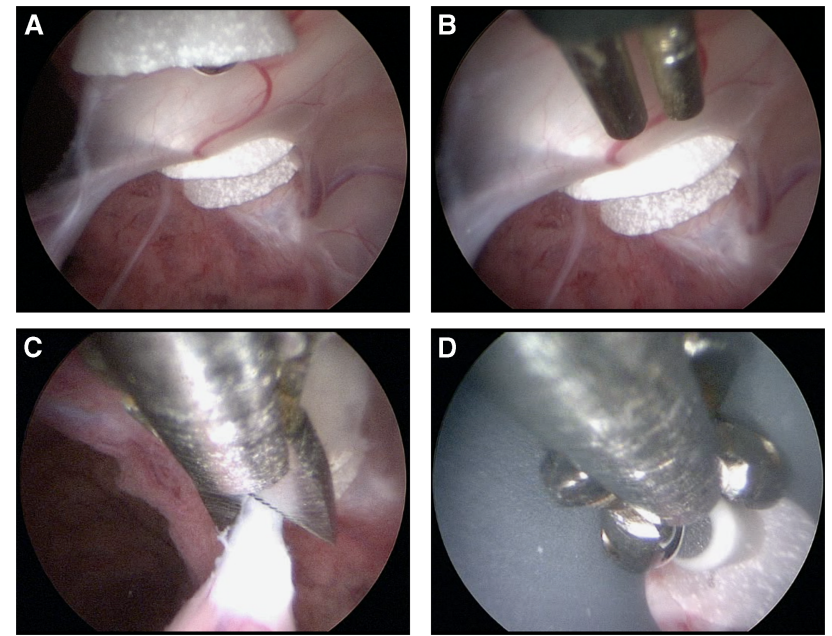

Figure 4: The sequential steps taken to mobilize and remove the adherent flanged ventricular catheter in Patient 2. (A) The flanged catheter is adherent to the choroid plexus and ependymal surface of the ventricle. (B) Use of endoscopic bipolar electrocoagulator to cauterize adherent bands and choroid plexus attachments anchoring the catheter in place. (C) Use of scissors to facilitate further mobilization of the catheter. (D) The flanged ventricular catheter is retrieved and subsequently removed via the endoscopic port by applying traction on its distal (closed) end using endoscopic biopsy forceps.

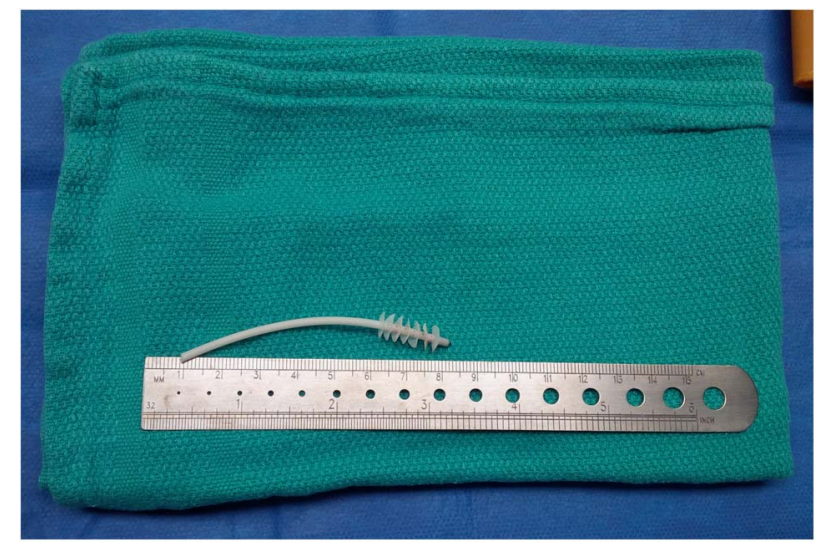

Figure 5: The explanted flanged ventricular catheter from Patient 2.

endoscopic forceps facilitated further mobilization of the catheter (Figure 4C). The flanged catheter was retrieved by applying traction on its closed proximal tip this time, and it was removed via the peel-away sheath (Figures 4D). An external ventricular drain was subsequently placed. The externalized flanged tip of the ventricular catheter is displayed in Figure 5. There were no perioperative complications noted from the endoscopic procedure.

Once the patient's CSF cultures cleared 18 days later, the external ventricular drain was removed and a new shunt system was placed. This shunt system did not become re-infected and remains functional and intact on follow-up 4 years later.

CSF shunt infections remain a vexing problem, with an incidence of $8-10 \% .^{3,5,6}$ Removal of CSF shunt components is desirable when treating a patient who has a shunt infection. Removal of ventricular catheters may be difficult due to adhesions between the catheter and surrounding structures, increasing the risk of hemorrhage.
Several techniques have been described for the removal of retained ventricular catheters, such as gentle traction on the distal end of the catheter, electrocautery, ultrasonography, or endoscopy. ${ }^{7-11}$ Ausman et al describe a technique for the removal of a simple flanged catheter through slow rotation of the catheter until the choroid plexus is detached from the catheter flanges. ${ }^{12}$ However, even in cases in which the surgeon has access to the catheter at its distal end at the level of the burr hole, removal of a retained ventricular catheter by gentle traction may not be feasible and may be complicated by intraventricular hemorrhage. In one series, intraventricular hemorrhage complicated $31 \%$ of revised ventricular catheters. ${ }^{9}$ To avoid such a complication, electrocautery may be recommended. Introduction of a metal stylet within the lumen of the catheter and application of electrocautery may be sufficient to break down the adhesions to the surrounding brain tissue. ${ }^{11}$ However, this method has been linked to charring and potential breakage of the ventricular catheter. ${ }^{13}$ Alternatively, the extraluminal use of an insulated suction device alongside electrocautery has also been described. ${ }^{8}$ Craniotomy for the removal of retained ventricular catheters is another alternative ${ }^{7}$ but may be associated with higher morbidity.

Sagan et $\mathrm{al}^{10}$ reported their results of endoscope-assisted revision of adherent ventricular catheters. Of the 29 cases that were reviewed, 13 revised ventricular catheters were tethered to the choroid plexus, seven to the ependyma, nine to the septum pellucidum, and five to blood vessels. In some cases, the endoscope was introduced through the same burr hole as the catheter, whereas in others through a different entry point (new ipsilateral or contralateral burr holes were drilled depending on the catheter location). ${ }^{10}$

The two patient cases reported in this paper involve ventricular catheters with their distal ends retracted from the burr hole. Endoscopic retrieval of retracted flanged catheters, as presented here, does not exist in current literature. Two variations of the endoscopic technique were performed to remove two flanged catheters of different designs. In the first case, a finned ventricular catheter (Integra LifeSciences Corporation, Plainsboro, New Jersey, USA) was removed via a right posterior parietal burr hole, applying traction on the open distal end of the catheter, whereas in the second case, a Portnoy ventricular catheter (Integra LifeSciences Corporation) was removed via a right frontal burr hole, applying traction on its closed proximal tip.

The removal of retained flanged ventricular catheters may pose a challenge to the neurosurgeon. Extraction of these catheters can be safely performed using an endoscopic technique.

\section{DisClosures}

M. Ege Babadagli, Dwaine Cooke, Simon A. Walling, P. Daniel McNeely have nothing to disclose.

\section{Statement OF AUThORShIP}

MEB, DC, and PDM: Study conceptualization, data collection, literature search, manuscript drafting, and review. SAW: Study conceptualization and manuscript review.

\section{REFERENCES}

1. Portnoy HD. New ventricular catheter for hydrocephalic shunts. J Neurosurg. 1971;34(5):702-3.

2. Haase J, Weeth R. Multiflanged ventricular Portnoy catheter for hydrocephalus shunts. Acta Neurochir. 1976;33(3-4):213-8. 
3. Browd SR, Ragel BT, Gottfried ON, Kestle JR. Failure of cerebrospinal fluid shunts: part I: obstruction and mechanical failure. Pediatr Neurol. 2006;34(2):83-92.

4. Hoffman HJ, Smith MSM. The use of shunting devices for cerebrospinal fluid in Canada. Can J Neurol Sci. 1986;13:81-7.

5. Kestle J, Drake J, Milner R, et al. Long-term follow-up data from the Shunt Design Trial. Pediatr Neurosurg. 2000;33(5):230-6.

6. Kulkarni AV, Drake JM, Lamberti-Pasculli M. Cerebrospinal fluid shunt infection: a prospective study of risk factors. J Neurosurg. 2001;94(2):195-201.

7. Vajramani GV, Jones G, Bayston R, Gray WP. Persistent and intractable ventriculitis due to retained ventricular catheters. Br J Neurosurg. 2005;19(6):496-501.

8. Chehrazi B, Duncan CC. Removal of retained ventricular shunt catheters without craniotomy. J Neurosurg. 1982;56(1):160-1.
9. Brownlee RD, Dold ONR, Myles ST. Intraventricular hemorrhage complicating the ventricular catheter revision: incidence and effect on shunt survival. Pediatr Neurosurg. 1995;22 (6):315-20

10. Sagan LM, Kojder I, Madany L. Endoscopic revision of adherent ventricular catheter: evaluation of the method. Neurol Neurochir Pol. 2005;39(4):294-9.

11. Whitfield PC, Guazzo EP, Pickard JD. Safe removal of retained ventricular catheters using intraluminal choroid plexus coagulation. J Neurosurg. 1995;83(6):1101-2.

12. Ausman JI, Portnoy HD, Amirjamshidi A. Shunts: which one, and why. Surg Neurol. 1998;49(1):8-13.

13. Handler MH. A complication in removing a retained ventricular catheter using electrocautery. Pediatr Neurosurg. 1996;25 (5):276. 